\title{
African same-sexualities and indigenous knowledge: Creating a space for dialogue within patriarchy
}

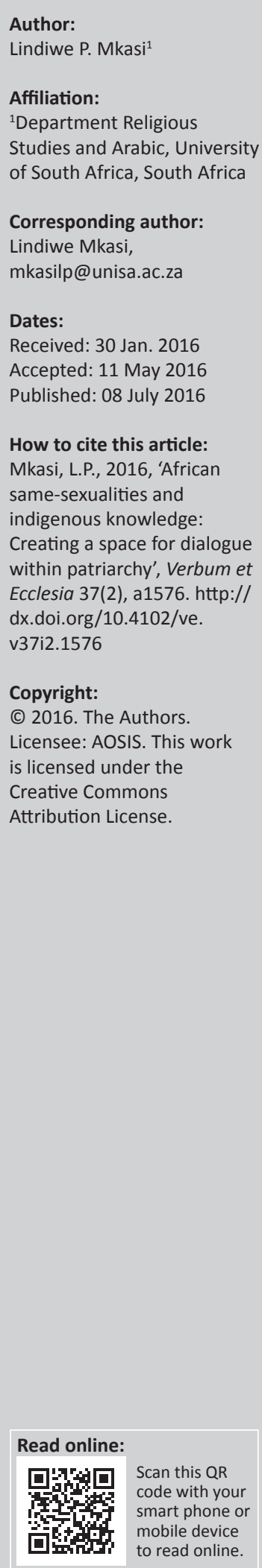

Current debates on homosexuality claim to give voice to the voiceless but only target the youth whose concern for freedom and rights differ markedly from older, more traditional concerns. Recent debates on same-sexualities are framed in a modern discourse and leave no room for traditional epistemologies. This article argues that knowledge of same-sexualities in African communities requires a far more complex narrative that is inclusive of indigenous knowledge and culture and of the older generations that uphold them. South Africa has gone through many changes and there is a need for new knowledge to face new challenges that come with democracy. The assumption here is that some issues need attention in contemporary societies which have never been properly investigated. One such issue is African same-sexualities. Although there is a need to interrogate the issue of freedom of speech from Western theoretical impositions, same-sexuality research needs to be contextualised and analysed through the eyes of indigenous societies. This could be achieved by creating space for debates between traditional and modern communities.

Intradisciplinary and/or interdisciplinary implications: This article addresses African indigenous same-sexualities using indigenous ways of knowing to unpack the practice. The article suggests a different approach on African same-sex practice based on ancestral knowledge found in African traditional religion and in African culture. It will further demonstrate how this practice relates to issues of gender and religion in the South African context. It also disapproves Western discourse on African sexuality based on human rights approaches and transformation that ignore African cultural practice that affirm life.

\section{Experiencing the academic world}

From the years spent in institutions of higher learning, I realised that the priority of these institutions is to produce new knowledge. I also realised that in entering this learning space, everyone faces challenges depending on one's background. For students who are coming from disadvantaged communities, it takes time to internalise Western paradigms and the use of Western epistemologies acquired in these institutions. Firstly, the language of communication can be a stumbling block in understanding theories, methods and theoretical frameworks. Often all these concepts do not make sense because none relate to one's own knowledge and experiences. While universities enforce Western pedagogies, one's own identity as a non-Westerner slowly disappears. The knowledge received at the university distances African students from their own culture and beliefs. Being removed from things that one has always identified with creates an empty space. I was once confused by scholarly debates that constantly criticised African cultures and I thought, 'If this is what it means to be an academic I don't want to be one'. What concerned me most was the fact that South Africa has millions of people who strongly believe in African traditions. On the other hand, many African scholars strongly criticise African indigenous knowledge and refer to it as superstitious beliefs (Shizha 2013:6). While this was difficult to digest, it practically means that the next generation would lose interest in their culture and adopt Western culture. I was trapped in a difficult space of being unable to communicate my frustrations and thoughts because I was studying in a foreign language and expected to use foreign experiences to research my context. This was a great challenge, but through it all I had to find my own space.

Fortunately, having a mentor or a supervisor and a sister such as Professor Isabel Apawo Phiri got me through this crisis. She mentored me through most of my studies and in my personal life. Being her research assistant made me understand the purpose and importance of research. My interest in conducting research on African same-sexualities grew out of her research. Phiri and her colleague, Professor Sarojini Nadar, worked on a project titled Broken women: Healing traditions? Indigenous resources for gender critique and social transformation in the context of HIV in rural Inanda and KwaNgcolosi. During one of the workshops they organised, the topic of same- 
sex relationships came up in the context of HIV prevention. One of the participants who was a sangoma (traditional healer) openly confessed that she had taken a decision to engage in a same-sex relationship because her husband refused to go for HIV testing (Phiri \& Nadar 2009:5-22). As the project at hand was not about homosexuality, we could not delve into the subject. I therefore decided to take this issue further while studying for my Master's degree. My research topic was 'A threat to Zulu patriarchy and the continuation of community': Same sex relationships amongst Female Traditional Healers at Inanda and KwaNgcolosi, KwaZulu Natal. The objective of the research was to investigate the (isa-is a singular while iza is a plural form) izangoma's same-sex experiences in traditional societies; the intention was to find out whether izangoma experience violence that many homosexual men and women experience in the society. The study revealed that ancestral spirits play an important role in same-sex relationships, but to understand the context of traditional healing one needs to get a background on spirit possession.

\section{Gender troubles within traditional healing}

In traditional healing, spirit possession plays a crucial role and there is an understanding that ancestral spirits can influence and change one's behaviour. It is not strange to see a male sangoma behaving like a female sangoma or a female sangoma who behaves like a male. At times, ancestral spirits take control of a body of a sangoma. In extreme cases, a spirit can completely take control of one's body depending on the ancestral spirit that possesses a person. Moreover, it is expected that ancestral spirits cross gender boundaries. To substantiate these claims, I will give a background of how spirit possession is interpreted in a traditional healing context, drawing from the author's dissertation (Mkasi 2013). Evidence shows spirits possess izangoma in five different ways, which are as follows:

A female spirit in a female sangoma.

A male spirit and a female spirit in a female sangoma.

A male spirit in a female sangoma.

An authoritative male spirit in a female sangoma.

A female spirit in a male sangoma. (Mkasi 2013:44)

When these categories are to be analysed in Western concepts of homosexuality they mean the following:

Lesbian - A female sangoma who is possessed by a female spirit. Bisexual - A female sangoma who is possessed by a female spirit and a male spirit.

Transgender - A female sangoma who is possessed by a male (authoritative) spirit.

Gay - A male sangoma who is possessed by a female spirit. (Mkasi 2013:44)

Firstly, ancestors are highly respected in traditional communities. The fact that izangoma are possessed by ancestral spirits puts them at the top of the hierarchy because ancestors are known to have power to punish or protect people. Secondly, when an authoritative male spirit possesses a female sangoma and that sangoma assumes a male position - she is addressed as uBaba (father), not only by izangoma but also by members of the community (Nkabinde 2008:59-60). This would normally happens during divination, but when they come across this type of a sangoma outside her traditional healing duties she is addressed as 'Makhosi' which is a concept that has no gender implications. This term is used to refer to all traditional healers, male or female. This type of a sangoma impersonates a male figure in such a way that members of the family will be able to identify who is the ancestor possessing her. This sangoma prefers not to marry because a male ancestor usually causes problems in the relationship. Alternatively, she may choose a celibate life, choose same-sex partners, or an 'ancestral wife', which may be an instruction from the ancestors (Morgan \& Reid 2003:378-379).

Having explained the spirit possession in a sangoma's life, the obvious question would be, can ancestors influence one's sexual behaviour? There is no easy answer to this question because being possessed by an opposite spirit does not mean that one will be in a same-sex relationship. Secondly, to confirm this, one has to hear from a person who is in this relationship and who has disclosed her sexuality. This is not always possible in traditional societies because these are taboo issues. This depends in the context wherein that sangoma is located. Izangoma who live in urban settings are open about their sexuality compared with those in rural areas; according to the author's findings, most female izangoma who participated in the study confirmed that these relationships are sexual as some practiced samesex relationships (Mkasi 2013:50).

There are few writers who have recently acknowledged the role of ancestors in same-sex practice; to name a few: Morgan and Wieringa (2005), Morgan and Reid (2003), Nkabinde (2008). Nkabinde has written about her life as a lesbian sangoma and she shares the stories of other izangoma who are in same-sex relationships. Nkabinde's work proves that in African patriarchy there is a place for women. Phiri is one of the African feminist scholars who touched on the subject, although she does not go deep into it (Mkasi 2013:11). In the traditional healing context, a patriarchal system does not work in favour of men but it benefits women. They assume superior positions in the society and men have been silenced by powers of female traditional healers.

\section{Safe space within patriarchy}

As much as this is complicated and challenging to understand, izangoma seem to have found a safe space within patriarchal system. Evidence from the author's study shows that samesex practice within the traditional healing context is different from contemporary homosexuality which is supported by equality and rights. Same-sexualities in this context do not shake the foundation of patriarchy or social order. Neither does it interfere with beliefs of procreation or threaten manhood. The homosexuality that occurs within the parameters of traditional healing does not need social 
recognition because matters relating to traditional healers are not public issues (Dlamini 2006:13). Whatever happens in a traditional healer's space is between izangoma and the ancestors. The community is expected to respect this space and they are aware of such boundaries. I am not suggesting that patriarchal men are happy about same-sex practice in traditional healing, but they have no voice in matters of traditional healing. Those who can argue against the practice are those who are in traditional healing and they understand complications that go with sprit possession. Furthermore, ordinary members of the community do not interfere with such issues unless they seek traditional healing. The question then will be, if this space is sacred to izangoma only, how then did the author access such sacred information?

To respond to this question, the author states: Conducting research as an academic and an African woman isangoma amongst izangoma was a challenge. Although I had an advantage as an insider, at times, it was difficult to be isangoma and a researcher at the same time because one was at the risk of being labelled as a traitor (cf. Smith 1999:139). Noteworthy, is the fact that in this kind of research one's expectations are not met, irrespective of prior preparation. Nevertheless, access to the information would have not been possible had I been an outsider. Considering that I was in that space to talk about homosexuality, in the context where there is no discussion about sex, my position as an insider helped the participants to share information freely. Flexibility was also encouraged based on the shared concerns about homosexual women who are being killed because of their sexual orientation. Being an insider gave me the opportunity to be in the space where a discussion about homosexuality takes place openly.

The insider position worked to the advantage of the author in this research, although there are disadvantages. In this context it was crucial for a researcher to be an insider in order not to be treated as an outsider. Hence she would not have had access to such secretive information. The intension of secrecy is to protect the community from possible harm that may come as a result of sacred information falling into the wrong hands (Breidlid 2009:146). Thus Tong (2010) says:

Conceptually, secrecy provides a form of protection that may either already be part of an existing custom, for example where certain sacred rites or practices are known only to certain members of the community. (pp. 161, 180)

During this research, the author discovered that ceremonies are used as a safe space where izangoma spend the whole night together and that is where they disclose about private issues without the presence of ordinary members of the community. However, it should be noted that not all traditional healers practice homosexuality, but they understand that spirits cross genders. Therefore, everyone participates in the discussion; at times, they use language that can only be understood by those involved in same-sex relationships to keep the discussion within the group in case members of the family in which the ritual is being performed are present. This language is used more or less like gay code, but it is not similar to the gay language known as isingqumo. Isingqumo is a Zulu word which can be translated into 'private talk'; issues that are referred to ukungqumuza are those that are secretive, not for public. This language is used by the gay community to keep the conversation within the group, but the language is mostly used in urban settings, especially in townships. (Rudwick 2011:99). It is important to note that this sexual discourse does not take place in the presence of children; if there are initiates who are younger they are sent out to do chores.

\section{African perspective on patriarchy}

The nature of the patriarchal system that operates in traditional societies is one issue that is contested by Western and some African feminists. Nonetheless, African traditional healing is based on patriarchy; one cannot practice traditional healing and claim not to be part of the system. The argument that persists against patriarchy about women's exploitation by men is not applicable in this context (Abelove, Barale \& Halper 1993:229). Radical feminists such as Tong (in Soares \& Batson-Rollock 2010) see patriarchy as the system that should be 'ripped out root and branch' (pp. 2-3). It is further described as a system which perpetuates gender inequality and sees the male gender as superior to the female gender. Even though gender inequality exists in traditional communities, feminist approaches could deteriorate the situation because outside interventions often disrespect traditional ethical protocol of respect. Thus, Cobbah (1987) says, 'Even if there are injustices of many types in traditional societies, it is not necessary to turn all people into westerners' (p. 328).

Gender inequality is stated as the main challenge faced by homosexual people who struggle under the patriarchal system. Female homosexuality threatens male domination and challenges masculinity (Abelove, Barale \& Helper 1993:239). But this problem is not applicable to all patriarchal societies; some communities are patriarchal but do not necessarily have all the characteristics of a patriarchal system. One such example is the community of traditional healers. In this context, gender inequality discourse is not a concern because of the belief in spirits which cut across gender boundaries (Mkasi 2013:44). Therefore, the deconstruction of patriarchy proposed by feminists is not necessary as homosexuality is practised within the parameters of the patriarchal system. Besides, deconstruction of patriarchy does not give assurance that prejudice and attitudes associated with homosexuality will come to an end. Therefore, African homosexuality should be closely scrutinised within African description and analysis of patriarchy. It is important to contextualise patriarchal discourse within the socio-history of the particular society in order to give specific meanings to any gender analysis (Soares \& Batson-Rollock 2010:3).

Furthermore, male leadership and authority, which are disputed so much by feminists, do not automatically give men the right to oppress women, but that authority comes with accountability, reciprocity and respect as well as the 
maintenance of order in the household. Obedience and respect are used as tools to maintain order in the society and in the household. Obedience and respect are used as tools to bring peace and order rather than perceived as submissive signs. As Johnson (in Gwyn 2003) rightly puts it, patriarchy is 'about how social life is and how it is supposed to be, about what is expected of people' (p. 29). This requires order as everyone acts responsibly in his or her role. Patriarchy in traditional communities is not specifically designed to undermine women but such behaviour is promoted by individual attitudes, not the system. Johnson argues that there is a tendency to discuss the system without considering the characteristics of the people who participate in it whereas individual behaviours have great impact on shaping the society (Gwyn 2003:27).

Furthermore, in patriarchal societies, gender roles are assigned in relation to physical ability, naturalness and sensitivity more than oppressive roles or to subordinate female gender. To implement gender equality in the household will require a shift in roles whereby males take up female roles and vice versa. Taking into account the fact that some roles are not socially constructed, but natural, changing roles would mean that women would have to give up their natural right to give birth, whereas men have no ability to give birth or breastfeed. Moreover, most women would not like to give up that right for equality. If gender equality discourse insists on this worldview without revisiting, indigenous discourse, this will complicate the patriarchal discourse and will definitely cross cultural boundaries (Gwyn 2003:27, 29). From my observation, gender equality discourse has neglected the issue of African maleness, men's role as protectors is not important anymore. The strength of African men that used to be the shield of the society is replaced by democratic laws. In fact, equality discourse puts more pressure on women who want to prove that they have the ability to do what men can do while their bodies are often weaker than men's bodies. Women still have to carry a child for 9 months, give birth, look after the baby and also continue to work.

Patriarchy is about making sure that men work to provide for their families, when mothers experience vulnerability when giving birth. While this article is trying to highlight positive elements in patriarchy it does ignore the negative elements in patriarchal systems, but those can be reconstructed and some gender roles can indeed be transformed, redefined and renegotiated rather than destroyed. But deconstructing social understanding of hetero-normativity of gender roles in the name of patriarchy devalues traditional communities (Sullivan 2003:81). Since traditional structures operate within the patriarchal system and they are disseminated through cultural beliefs and traditions, ripping out 'root and branch' of patriarchy as Tong (1989) suggest (in Soares \& BatsonRollock 2010:3-4) will totally destroy African traditional culture. Therefore, I suggest that patriarchal discourse should not be analysed and generalised superficially but rather be seen in the context of historical and cultural impact on the society.
Some cultural practices that are being criticised by feminists bring life to the community and they are not at all life threatening. Discussing these practices within equality and right framework is not appropriate because leaders and practitioners of these practices are not included in these discourses. They are voiceless, while activist, scholars and policy-makers are speaking on their behalf. Thus, traditional communities give less attention to changes taking place in South Africa, because they feel excluded and therefore distance themselves from transformation that takes place as results of the constitution (Van Zyl 2011:345).

\section{African sexual practice and democracy}

We should be careful of African discourses that are founded on Western discourse. When democratic government was inaugurated in 1994, South Africa adopted human rights laws which enforced abandonment of sexual cultural practice (Moseley 2004:205), even though the majority of African people strongly believe in such cultural practices (Gouws 2013:45). Traditional laws have been replaced by constitutional laws in response to the constitutional requirements of equality to everyone, whereas the same constitution does not recognise indigenous voices who are the practitioners of African traditions (Constitution, Chapter 2:9.1). Human rights laws, with their liberal approach, put strain on traditional laws since liberalism is constructed on individual rights and equal rights (Gouws 2013:36). Thus, Western notions are imposed on traditional communities without evaluating the impact on African cultural practices.

To substantiate this point, Chilisa argues that Western thought and education differ from indigenous knowledge systems, and are therefore unable to meet the needs of indigenous problems (Chilisa 2012:17). Practices such as virginity testing and ilobolo (bride price) are contested because beneficiaries of the practices are men. Virginity testing is described as a violation of human rights and an invasion of privacy (South African human Right Commission 2003:4) and ilobolo is interpreted as price paid by the groom for a bride (Scorgie 2002:612). These practices are rejected based on Western understanding of human rights. Thus, Nhlapho (in Gauws 2013) argues that:

\footnotetext{
In the African context, recognition also requires that we accept that there are conceptions of human dignity that are distinctly African and are involved in cultural practices that may look like subordination from a Western perspective. For example, ilobolo or the bride price is not the selling of women but the uniting of two different families and many women feel valued by this. So, the recognition of identities also requires respect for cultural practices. (p. 50)
}

While opposition to virginity testing focuses on technicalities of the practice, there is silence about the whole initiation process whereby children are taught life-affirming lessons such as HIV prevention, nature conservation, life-affirming songs and the history of the amaZulu (Scorgie 2002:55). Virginity testing is not only about the physical body of an 
individual, but it is intended to sustain a healthy land and the livelihood of the nation. Virginity testing is one of the practices that the Zulu nation prides itself in, as it does not only prepare women for marriage but also for a ritual of appeasement dedicated to Mother Nature, 'Nomkhubulwane' (Scorgie 2002:57). Biyela (2013) confirms that:

Nomkhubulwane is regarded as a powerful female intercessor during times of catastrophe such as drought. The Zulu believe that before Nomkhubulwane implores with God for rain, she goes to the mountain where she has to be surrounded by other girls marked with strings of white beads around their lower waists; their purity encourages Mother Nature to give more food. (p. 38)

This practice was and is still performed in recognition of the Zulu female goddess, and it remains in effect. However, the ritual is not performed to benefit the individual alone but the whole nation in accordance with African philosophy. While political and traditional leaders argue about virginity testing practices, some have seen it as a business opportunity. Virginity testing has been so commercialised that it has become a tourist attraction (Nkosi 2013:1). The media has full access to initiation rooms, which in this context is not seen as a violation of the right to privacy. Its commercialisation does not improve the practice but only increases the country's economy and puts the top political leaders in the limelight. Nkosi (2013) argues, 'Ceremonial events should not end up being commercialized and performed to attract tourists only, but to achieve their initial and traditional purpose' (Nkosi 2013:18). A lack of initial purpose of the practice results in disrespect and false interpretations of the practice which demean the dignity of African traditions. Ilobolo is also not exempted from the problem of commercialisation; the meaning of ilobolo has changed. It is no longer about building a relationship between two families, but it is about exchanging goods. This change is rationalised by the level of education of the bride which changes the whole concept of ilobolo.

Regardless of Western feminists' ignorance of African culture, African feminists have played an important role in voicing the concerns of woman in traditional societies. Women of concern, and theologians, made a great input in addressing the problem of universalism of women's issue. They have touched on a number of issues that directly affect African woman, such as oppression of women and violation of sexual rights and same-sexualities (Phiri \& Nadar 2006:11). But they also consider the fact that some of these problems are over emphasised, where the blame is continuously put on African culture. They acknowledge that women all over the world have common problems as a result of patriarchal system. Nevertheless, in the African context there are cultural aspects that are life affirming, as mentioned above, such as virginity testing (Phiri \& Nadar 2006:11). Although there are oppressive practices in African religio-culture, woman traditional healers have used the same culture to find their own place. They have claimed their position within the patriarchal system that is known to be oppressive to woman.

\section{Conclusion}

It seems indigenous ways of knowing may provide space for indigenous discourse on same-sexualities. Moreover, revising and contextualisation of African patriarchal systems can identify elements that are supportive to African women. Often, lives of African women are interpreted in Western values and standards which do not give true reflection of their experiences. Even though some African feminists have reviewed and critiqued Western theories on African women's sexualities, they cannot remove themselves from Western standards, whereas same-sex practice and discourse that occur within the traditional healing context are purely indigenous and are not influenced by Western paradigms. Moreover, indigenous discourses contain no Western terms or concepts; this means these discourses are not polluted by Western worldview.

Since izangoma are traditional leaders and are able to talk about their sexuality, this could be an opportunity to start such discourse in traditional communities where same sexuality is not accepted. Furthermore, scholars who work in the area of sexuality should start using tools of research that are appropriate for indigenous communities. This will enable them to access information that can help bring understanding of why there is so much resistance towards transformation in traditional communities. Political leaders should also consider the needs of indigenous communities, especially giving attention to the elders of the community because they are the archives of knowledge. Ignorance of cultural beliefs and labelling them as superstitious will only prevent flowing of knowledge from the older generation to younger generation, because our youth will not respect the voices of the elders as Western teachings emphasise individualism and self-centredness which result in selfish behaviour and undermine the African philosophy of Ubuntu.

Furthermore, lack of literature and African scholars who are interested in African indigenous same-sexualities is problematic for students who want to study this subject, because using Western literature to analyse African samesexualities weakens the analysis. Tamale says, 'the absence of African literature on same-sexualities is because the subject has been taken for granted' (Tamale 2011:12). But another possibility is that it has been purposely avoided by African scholars since it is a complex issue to investigate. Its nature of secrecy is even more complex for a researcher who is an insider. Probably feminist scholars themselves are not exempted from the culture of silence when it comes to taboo issues.

\section{Acknowledgements Competing interests}

The author declares that she has no financial or personal relationships which may have inappropriately influenced her in writing this article. 


\section{References}

Abelove, H., Barale, M.A. \& Helper, D.M., 1993, The lesbian and gay studies reader Routledge, New York.

Biyela, N.G., 2013, 'Colour metaphor in Zulu culture: Courtship communication in beads', American International Journal of Contemporary Research 3 (10), 37-41, viewed 29 November 2015, from http://www.aijcrnet.com

Breidlid, A., 2009, 'Culture, indigenous knowledge systems and sustainable development: A critical view of education in an African context', International Journal of Educational Development 29 (2009), 140-148, viewed 14 September 2015, https://www.deepdyve.com/.../culture-indigenous-knowledge-systems

Chilisa, B., 2012, Indigenous research methodologies, SAGE Publications, Los Angeles.

Cobbah, A.M., 1987, 'African values and the human rights debate: An African perspective', Human Right Quarterly 9 (3), 309-331, http://dx.doi.org/10.2307/ 761878

Dlamini, B., 2006, 'Homosexuality in the African context', Agenda: Empowering Women for Gender Equity 20 (67), 28-13, viewed 14 March 2014, from http://www.tandfonline.com

Gouws, A., 2013, 'Multiculturalism in South Africa: Dislodging the binary between Universal Human Rights and Culture/Tradition', Politikon: South African Journal of Political Studies, Studies 40 (1), 35-55, viewed 26 April 2014, from http://www. tandfonline.com

Gwyn, K., 2003, Women's lives: Multicultural perspectives, McGraw-Hill College, Boston, MA.

Mkasi, L.P., 2013, 'A threat to Zulu patriarchy and the continuation of community: A queer analysis of same sex relationships amongst Female Traditional Healers at Inanda and KwaNgcolosi, KwaZulu-Natal', Unpublished thesis (M.A), University of Kwa-Zulu-Natal, Pietermaritzburg.

Morgan, R. \& Wieringa, S., 2005, Tommy boys, lesbian men and ancestral wives: Female same sex practice in Africa, Jacana Press, Johannesburg.

Morgan, R. \& Reid, G., 2003, 'I've Got Two Men and One Woman': Ancestors, Sexuality and Identity among Same sex, Identified Women Traditional Healers in South Africa, viewed 04 June, 2009, from http://www.ingentaconnect.com

Moseley, W.G., 2004, Taking sides. Clashing views on controversial African issues, McGraw Hill, Boston.
Nkabinde, N.Z., 2008, Black bull, ancestors and me: My life as a lesbian Sangoma, Fanele, Johannesburg.

Nkosi, G.S., 2013, 'Umkhosiwohlanga (Reed Dance) as a tourism enterprise in KwaZulu-Natal: Perceptions, policies and practices', Unpublished thesis (PhD), University of Zululand, Kwa-Dlangezwa, Department of Recreation and Tourism.

Phiri, I.A. \& Nadar, S., 2009, 'Going through the fire with eyes wide open': African women's perspectives on Indigenous knowledge, Patriarchy and sexuality', Journal for the Study of Religion 22(2), 5-22.

Phiri, I.A. \& Nadar, S. (eds.), 2006, African women, religion, and health: Essays in honor of Mercy Amba Ewudziwa Oduyoye, Orbis Books, Maryknoll.

Rudwick, S., 2011, 'Defying a myth: A gay sub-culture in contemporary South Africa', Nordic Journal of African Studies 20(2), 90-111.

Scorgie, F., 2002, 'Virginity testing and the politics of sexual responsibility: Implications for AIDS intervention', African Studies 61(1), 55-75, viewed 23 November 2015 from http://citeseerx.ist.psu.edu

Shizha, E., 2013, 'Reclaiming our indigenous voices: The problem with postcolonial Sub-Saharan African school curriculum', Journal of Indigenous Social Development 2(1), 1-18, viewed n.d., from https://scholarspace.manoa.hawaii.edu/bitstream

Smith, L.T., 1999, Decolonizing methodologies: Research and indigenous people, Zed Books, London.

Soares, J. \& Batson-Rollock, C., 2010, 'Rethinking "patriarchy"' in a rural context, viewed 24 November 2015, from http://www.open.uwi.edu/.../Theoretical\%20 Contextfeminism $\% 20$ soares $\% 20$ an

South African human Right Commission, 2003, 'Harmful social and cultural practices? South African human Right Commission', viewed 22 November 2015, from http://www.sahrc.org.za

Sullivan, N., 2003, A critical introduction to queer theory, New York University Press, New York.

Tamale, S. (ed.), 2011, African sexualities: A reader, Pambazuka, Oxford, UK.

Tong, L.A., 2010, 'Protecting traditional knowledge-Does secrecy offer a solution?' PER / PEL 2010 (13), 4, viewed 13 September 2015, from http://www.nwu.ac.za

Van Zyl, M., 2011, 'Are same-sex marriages Un-African? Same-sex relationships and belonging in post-apartheid South Africa', Journal of Social Issues 67(2), 335-357. http://dx.doi.org/10.1111/j.1540-4560.2011.01701.x 